\title{
Maternally Expressed Gene 3 (MEG3) Enhances PC12 Cell Hypoxia Injury by Targeting MiR-147
}

\author{
Lili Han $^{\mathrm{a}}$ Zhiling Dong ${ }^{\mathrm{a}}$ Ningning Liu ${ }^{\mathrm{a}} \quad$ Fei $\mathrm{Xie}^{\mathrm{b}} \quad$ Ning Wang $^{\mathrm{c}}$ \\ aDepartment of Neurology, Cangzhou Central Hospital, Cangzhou, 'The First Department of Pediatric, \\ Cangzhou Central Hospital, Cangzhou, 'Department of Electroneurophysiology, Cangzhou Central \\ Hospital, Cangzhou, China
}

\section{Key Words}

Meg3 • Cerebral ischemia • MiR-147 • Sox2 • PC-12 cells • Hypoxia $\cdot$ Long non-coding RNA

\begin{abstract}
Background/Aims: Cerebral ischemia often leads to breakdown of blood-brain barrier (BBB) and vasogenic edema. It remains to be established whether MEG3 is responsible for the hypoxic damage in neural cells. This study aimed to investigate the role of MEG3 in the hypoxia-induced injuries of PC12 cells. Methods: The PC12 cells were seeded and cultured under hypoxia and normoxia culture conditions. The cell viability determined by trypan blue exclusion, apoptosis using propidium iodide (PI) and fluorescein isothiocynate (FITC)conjugated Annexin $\mathrm{V}$ staining, cell-migration using a modified two-chamber migration assay with a pore size of $8 \mu \mathrm{M}$ and invasion using 24-well Millicell Hanging Cell Culture inserts with $8 \mu \mathrm{M}$ PET membranes. Results: Cell viability, relative migration and relative invasion decreased significantly in PC12 cells injured due to hypoxia as compared to control cells. An increase in apoptosis was also observed. The expression of MEG3 was up-regulated in hypoxiainjured PC12 cells. MEG3 overexpression enhanced hypoxia injuries, while MEG3 suppression attenuated the injuries. Meanwhile, MEG3 negatively regulated miR-147 expression. In addition, we found that the expression of Sox2 was increased in PC12 cells after hypoxia and miR-147 negatively regulated Sox2 expression through targets its $3^{\prime}-U T R$. Interesting, Sox2 activated NF-KB pathway and Wnt/ $\beta$-catenin pathway in PC12 cells. Conclusion: Considering the observations in our study, we can conclude that MEG3 aggravated the hypoxial injury in PC12 cells by down-regulating miR-147 gene and miR-147 further negatively regulated Sox2 expression.

(C) 2017 The Author(s)

Published by S. Karger AG, Basel
\end{abstract}

\section{Introduction}

Stroke, known as cerebrovascular disease, is a common and devastating neurological disease, which is characterized by high mortality and morbidity rates [1]. Ischemic stroke, 


\section{Cellular Physiology Cell Physiol Biochem 2017;43:2457-2469

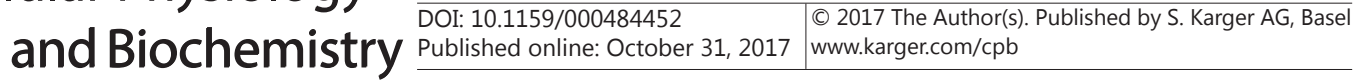 \\ Han et al.: Role of MEG3 in Cerebral Ischemia}

accounts for $80 \%$ of stroke, which is mainly caused by an insufficient supply of glucose and oxygen to central nervous system (CNS) tissue and thus resulting in a significant amount of cell damages [2]. A series of complex cellular and biochemical molecular mechanisms are involved in the pathology, such as the excitotoxicity, mitochondrial dysfunction, ionic imbalance, oxidative stress, and inflammation, eventually leading to a loss of neurological functions and even cell death $[3,4]$. Hypoxia is a critical factor for cell death or survival in ischemic stroke [5]. In the beginning of cerebral ischemia, the regional oxygen extraction fraction is increased, thus compensating for the reduced cerebral blood flow (CBF) and to maintain the cerebral metabolic rate of oxygen close to the normal value [6]. Subsequently, there often occurs a reduction of oxygen extraction fraction and cerebral metabolic rate of oxygen even with the regional CBF maintained in the penumbra range, which indicates imminent infarction [7, 8]. Imaging studies have shown that the reduction of the oxygen extraction fraction and the cerebral metabolic rate of oxygen are critical predictors of irreversible tissue damage $[9,10]$. It suggests that hypoxia is pivotal for determination for the fate of the brain tissue, resulting from whether receiving inadequate blood supply. Although emerging studies dedicated to explore the cellular and molecular bases of cerebral ischemia, there still remains extreme limitations in the investigations of the specific and potent treatment for the neuronal functional recovery after cerebral ischemic stroke [11, 12]. Regard to the destructive impact and social burden of this damaging cerebrovascular event, the development of optimum treatments for ischemic stroke is urgently needed [13].

Increasing evidences revealed that microRNAs (miRNAs) are important regulators of gene expression through degradation or repression of their target predicted genes and play crucial role in the initiation and progression of various kinds of diseases [14]. Recently, it has been reported that miRNAs have key roles in the pathophysiological processes contributing to ischemic stroke injuries and several miRNAs are involved in recoveries and repair mechanisms for neuroprotection [15]. miRNAs have participated as key mediators in several pathogenic processes including excitotoxicity, oxidative stress, inflammation and apoptosis through down-regulating the gene expression $[15,16]$. Long non-coding RNAs (lncRNAs) are nonprotein coding transcripts longer than 200 nucleotides, and many of which are emerged as an important class of regulatory molecules in governing fundamental biological processes [17]. LncRNAs can suppress precursor mRNA splicing and translation by acting as decoys for RNA-binding proteins or miRNAs, or as competing endogenous RNAs to sponge miRNAs resulting in increased expression of corresponding proteins [18]. Although a series of lncRNAs has been reported to linked to neurodegenerative disorders including Alzheimer's disease (AD), Parkinson's disease (PD), and Huntington's disease (HD), the role of lncRNAs in stroke remains unclear $[19,20]$.

Maternally Expressed Gene 3 (MEG3), an imprinted gene with maternal expression, plays a role in cell proliferation by interacting with other factors, such as cyclic AMP, p53, murine double minute 2 (MDM2), and growth differentiation factor 15 (GDF15) [21, 22]. Recent study has reported that MEG3 enhanced cell death through interaction with p53 and mediated ischemic damage [23]. However, it is yet to be further explored the role of MEG3 in the hypoxic damage and underlying mechanism in neural cells. Thus, the present study aimed to investigate the role of MEG3 in hypoxia-induced PC12 cell injuries and its regulatory mechanism.

\section{Materials and Methods}

Cell culture and treatment

The PC12 cells were purchased from Kunming Institute of Zoology (Kunming, China). PC12 cells are pheochromocytoma of the rat adrenal medulla, that has an embryonic origin from the neural crest that has a mixture of neuroblastic cells and eosinophilic cells. The cells were seeded onto flasks at a density of $1 \times 10^{4}$ cells/ml in Dulbecco's modified Eagle Medium (DMEM) (Sigma-Aldrich, St. Louis, MO, USA) with 10\% (v/v) fetal bovine serum (FBS; Hyclone, Logan, UT, USA), $100 \mathrm{U} / \mathrm{ml}$ penicillin and $100 \mu \mathrm{g} / \mathrm{ml}$ streptomycin (Gibco, 


\section{Cellular Physiology Cell Physiol Biochem 2017;43:2457-2469 \begin{tabular}{ll|l} 
and Biochemistry Published online: October 31, 2017 & $\begin{array}{l}\text { C } 2017 \text { The Author(s). Published by S. Karger AG, Basel } \\
\text { www.karger.com/cpb }\end{array}$ \\
\hline
\end{tabular} \\ Han et al.: Role of MEG3 in Cerebral Ischemia}

Life Technologies, Grand Island, NY). It was maintained at $37^{\circ} \mathrm{C}$ in a humidified incubator containing $5 \%$ $\mathrm{CO}_{2}$. Culture medium was changed every other day. The cultures were maintained at $3 \% \mathrm{O}_{2}$ concentration for hypoxic condition and at $21 \% \mathrm{O}_{2}$ concentration for normal condition.

Primary cortical neurons were isolated from embryonic day 16-18 Sprague-Dawley rats and cultured as described previously [24]. Briefly, the cerebral cortices were dissected and digested in trypsin. Dispersed cells were diluted to a concentration of $1 \times 10^{6}$ cells $/ \mathrm{ml}$ and plated on poly-L-lysine $(50 \mu \mathrm{g} / \mathrm{ml}$ ) (SigmaAldrich, St. Louis, MO, USA) pre-coated plates in neurobasal medium, containing $5 \%$ fetal bovine serum (FBS) (Thermo Fisher Scientific, San Jose, CA, USA), 2 \% (v/v) B27 serum-free supplement (Thermo Fisher Scientific), $0.5 \mathrm{mM}$ L-glutamine and $25 \mu \mathrm{M}$ glutamate (Thermo Fisher Scientific) at $37{ }^{\circ} \mathrm{C}$ in a humidified incubator containing $5 \% \mathrm{CO}_{2}$. On day 3 , half of the medium was replaced by fresh one (neurobasal meidium without $25 \mu \mathrm{M}$ glutamate) every 2 days. The cells were used for experiments between 6 and 9 days in vitro.

\section{Quantitative real-time PCR assay ( $q R T-P C R$ )}

Total RNA was extracted from cells using Trizol reagent (Life Technologies Corporation) according to the manufacturer's instructions. One Step SYBR ${ }^{\circledR}$ PrimeScript ${ }^{\circledR}$ PLUS RT-RNA PCR Kit (TaKaRa Biotechnology), was used to test the expression levels of MEG3. Taqman MicroRNA Reverse Transcription Kit and Taqman Universal Master Mix II with TaqMan MicroRNA Assay of miR-147 and U6 (Applied Biosystems, Foster City, CA, USA) were used for the expression levels of miR-147 in cells. For the test of Sox2, RNA PCR Kit (AMV) Ver.3.0 (TaKaRa Biotechnology) was used. GAPDH was used in this study as endogenous control. The normalizing Fold changes were calculated by relative quantification $\left(2^{-\Delta \Delta \mathrm{Ct}}\right)$ method.

\section{Transfection and generation of stably transfected cell lines}

Short-hairpin RNA directed against human lncRNA MEG3 was ligated into the U6/GFP/Neo plasmid (GenePharma, Shanghai, China) and was referred as to sh-MEG3. Plasmids overexpression MEG3 was ligated into the pcDNA3.1 and was referred as to pc-MEG3. For the analysis of the Sox2 functions, the fulllength Sox2 sequences and short-hairpin RNA directed against Sox2 were constructed in pEX-2 and U6/ GFP/Neo plasmids (GenePharma), respectively. And they were referred as to pEX-Sox2 and sh-Sox2. The lipofectamine 3000 reagent (Life Technologies Corporation, Carlsbad, CA, USA) was used for the cells transfection according to the manufacturer's instructions. The plasmid carrying a non-targeting sequence was used as a negative control (NC) of sh-MEG3 and sh-Sox2 that was referred as to sh-NC. The stably transfected cells were selected by the culture medium containing $0.5 \mathrm{mg} / \mathrm{ml} \mathrm{G} 418$ (Sigma-Aldrich). After approximately 4 weeks, G418-resistant cell clones were established. MiR-147 mimics, inhibitors and their respective NC were synthesized (Life Technologies Corporation, MD, USA) and transfected into cells in the in the study. Because the highest transfection efficiency was occurred at $48 \mathrm{~h}$, thus $72 \mathrm{~h}$ post-transfection was considered as the harvest time in the subsequent experiments.

\section{miRNA transfection}

miR-147 mimic, miR-147 inhibitor, and the corresponding negative controls (Sramble, inhibitor control) constructs were synthesized by GenePharma. Cell transfections were conducted using Lipofectamine 3000 reagent (Invitrogen, Carlsbad, CA, USA) following the manufacturer's protocol. PC12 cells were seeded the prior day and then transfected with miR-147 mimic, miR-147 inhibitor, and the corresponding negative controls. The cells were processed for further analysis after transfection for $48 \mathrm{~h}$.

\section{Cell proliferation assays}

For cell proliferation assay, $1 \times 10^{5}$ cells were seeded in duplicate in $60-\mathrm{mm}$ dishes. At the indicated time periods, cells were washed phosphatebuffered saline (PBS) and live cell numbers were determined by trypan blue exclusion (Beyotime Biotechnology, Shanghai, China) as previously described [25].

\section{Apoptosis assay}

Cell apoptosis analysis was performed using propidium iodide (PI) and fluorescein isothiocynate (FITC)-conjugated Annexin V staining (Beyotime Biotechnology, Shanghai, China). Briefly, cells were washed in phosphatebuffered saline (PBS) and fixed in 70\% ethanol. Fixed cells were then washed twice in PBS and stained in PI/FITC-Annexin V in the presence of $50 \mu \mathrm{g} / \mathrm{ml}$ RNase A (Sigma-Aldrich), and then incubated for 1 $\mathrm{h}$ at room temperature in the dark. Flow cytometry analysis was done by using a FACS can (Beckman Coulter, Fullerton, CA, USA). The data were analyzed by using FlowJo software. 


\section{Cellular Physiology Cell Physiol Biochem 2017;43:2457-2469 \begin{tabular}{l|l|l} 
and Biochemistry & Published onlline: October 31, 2017 & $\begin{array}{l}\text { C } 2017 \text { The Author(s). Published by S. Karger AG, Basel } \\
\text { www.karger.com/cpb }\end{array}$
\end{tabular}}

Han et al.: Role of MEG3 in Cerebral Ischemia

Migration and invasion assay

Cell migration was determined by using a modified two-chamber migration assay with a pore size of $8 \mu \mathrm{M}$. For migration assay, cells suspended in $200 \mu \mathrm{l}$ of serum-free medium were seeded on the upper compartment of 24-well Transwell culture chamber, and $600 \mu \mathrm{l}$ of complete medium was added to the lower compartment. After incubation at $37^{\circ} \mathrm{C}$, cells were fixed with methanol. Non-traversed cells were removed from the upper surface of the filter carefully with a cotton swab. Traversed cells on the lower side of the filter were stained with crystal violet and counted.

The invasion behavior of was determined using 24-well Millicell Hanging Cell Culture inserts with $8 \mathrm{~mm}$ PET membranes (Millipore, Bedford, Massachusetts, USA). Briefly, after the cells were treated for indicated condition, $5.0 \times 10^{4}$ cells in $200 \mu \mathrm{l}$ serum-free DMEM medium were plated onto BD BioCoatTM Matrigel TM Invasion Chambers ( $8 \mu \mathrm{M}$ pore size polycarbonate filters; BD Biosciences), while complete medium containing $10 \%$ FBS was added to the lower chamber. After processing the invasion chambers for 48 hours $\left(37^{\circ} \mathrm{C}, 5 \% \mathrm{CO}_{2}\right)$ in accordance with the manufacturer's protocol, the non-invading cells were removed with a cotton swab; the invading cells were fixed in $100 \%$ methanol and then stained with crystal violet solution and counted microscopically. The data are presented as the average number of cells attached to the bottom surface from five randomly chosen fields.

\section{Reporter vectors constructs and luciferase reporter assay}

The fragment from MEG3 containing the predicted miR-147 binding site was amplified by PCR and then cloned into a pmirGlO Dual-luciferase miRNA Target Expression Vector (Promega, Madison, WI, USA) to form the reporter vector MEG3-wild-type (MEG3 -Wt). To mutate the putative binding site of miR-147 in the MEG3, the sequence of putative binding site was replaced and was named as MEG3-mutated-type (MEG3 -Mt). Then the vectors and miR-147 mimics were co-transfected into HEK 293T cells, and the DualLuciferase Reporter Assay System (Promega) was used for testing the luciferase activity.

\section{Western blot}

The protein used for western blotting was extracted using RIPA lysis buffer (Beyotime Biotechnology) supplemented with protease inhibitors (Roche, Basel, Switzerland). The proteins were quantified using the BCA $^{\text {TM }}$ Protein Assay Kit (Pierce, Appleton, WI, USA). The western blot system was established using a BioRad Bis-Tris Gel system according to the manufacturer's instructions. Primary antibodies (Table 1) were prepared in 5\% blocking buffer at a dilution of 1:1, 000 and the catalogue numbers were shown in Table 1. Primary antibody was incubated with the membrane at $4^{\circ} \mathrm{C}$ overnight, followed by wash and incubation with secondary antibody marked by horseradish peroxidase for 1 hour at room temperature. After rinsing, the Polyvinylidene Difluoride (PVDF) membrane carried blots and antibodies were transferred into the Bio-Rad ChemiDoc ${ }^{\mathrm{TM}}$ XRS system, and then 200 $\mu$ Immobilon Western Chemiluminescent HRP Substrate (Millipore, MA, USA) was added to cover the membrane surface. The signals were captured and the intensity of the bands was quantified using Image Lab ${ }^{\text {TM }}$ Software (Bio-Rad, Shanghai, China).

\section{Statistical analysis}

All experiments were repeated three times. The results of multiple experiments are presented as the mean \pm SD. Statistical analyses were performed using Graphpad 6.0 statistical software. The P-values were calculated using a one-way analysis of variance (ANOVA). A P-value of $<0.05$, P-value $<0.01$ and $\mathrm{P}$-value $<0.001$ was considered to indicate a statistically significant result.

Table 1. Primary antibodies used in current study

\begin{tabular}{lcll}
\hline Antibody & Dilution & Supplier & Cat.No \\
\hline Bax & $1: 1000$ & Cell Signaling Technology & $\# 5023$ \\
Bcl-2 & $1: 1000$ & Cell Signaling Technology & $\# 3498$ \\
& & \\
Caspase3 & $1: 1000$ & Cell Signaling Technology & $\# 9665$ \\
& & \\
Caspase9 & $1: 1000$ & Cell Signaling Technology & $\# 9508$ \\
Sox2 & $1: 1000$ & Cell Signaling Technology & $\# 14962$ \\
& & & \\
GAPDH & $1: 1000$ & Cell Signaling Technology & $\# 2118$
\end{tabular}




\section{Cellular Physiology Cell Physiol Biochem 2017;43:2457-2469

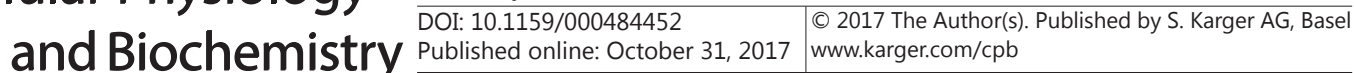 \\ Han et al.: Role of MEG3 in Cerebral Ischemia}

\section{Results}

\section{Hypoxia induces cell injury in PC12 cells}

To induce hypoxic injury, PC12 cells were cultured at 3\% oxygen concentration; the cells cultured at normal oxygen concentration were used as control. The hypoxic condition significantly decreased cell viability $(\mathrm{P}<0.05$; Fig. $1 \mathrm{~A})$, migration $(\mathrm{P}<0.05$; Fig. $1 \mathrm{~B})$, and invasion $(\mathrm{P}<0.05$; Fig. $1 \mathrm{C})$, and increased apoptotic cell rates $(\mathrm{P}<0.001$; Fig. $1 \mathrm{D})$ of $\mathrm{PC}-12$ cells as compared to the control cells. We also assessed the protein expression of apoptosisrelated core factors in PC12 cells after hypoxia treatment. As shown in Fig. 1E, the hypoxic condition significantly reduced the Bcl-2 expressions, while increased the levels of Bax, cleaved-Caspase- 3 and cleaved-Caspase- $9(\mathrm{P}<0.01$ or $\mathrm{P}<0.001)$. These results indicated that hypoxia induced cell injuries in PC12 cells.

Over-expression of MEG3 aggravates hypoxia injury in PC12 cells, while suppression of MEG3 alleviates the injury

Firstly, we investigated the expression changes of MEG3 in PC12 cells after hypoxia. As shown in Fig. 2A, MEG3 expression was significantly increased in PC12 cells after hypoxia treatment. Similar result was found in the primary cortical neurons (Fig. 2A). Then we explored the role of MEG3 in hypoxia-injured PC12 cells. PC12 cells were transfected either with pc-MEG3 or sh-MEG3 and the efficiency of transfection was performed by qRT-PCR analysis. Enhanced MEG3 expression was observed in PC12 cells transfected with MEG3, referred to as pc-MEG3 compared to pcDNA3.1 ( $\mathrm{P}<0.001$; Fig. 2B). On the contrary, expression

Fig. 1. Hypoxia induces cell injury in PC12 cells. Hypoxia induces hypoxia injury in PC12 cells inhibits (A) cell viability measured by trypan blue exclusion, (B) migration determined by a modified two-chamber migration assay with a pore size of $8 \mu \mathrm{M}$, (C) invasion determined by 24-well Millicell Hanging Cell Culture inserts with 8 $\mu \mathrm{M}$ PET membranes and promotes (D) cell apoptosis measured by propidium iodide (PI) and fluorescein isothiocynate (FITC)-conjugated Annexin V staining; (E) Cell apoptosis measured by western blot.*, $\mathrm{P}<0.05$; **, $\mathrm{P}<0.01$; ***, $\mathrm{P}<0.001$.
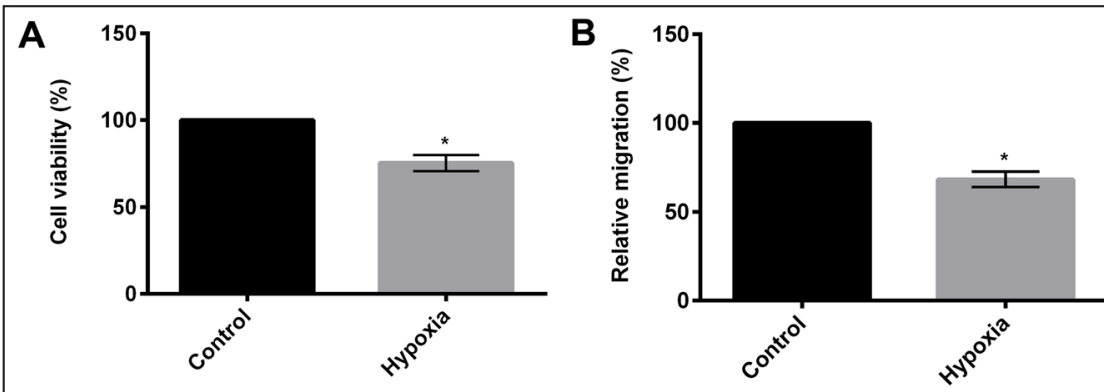

C
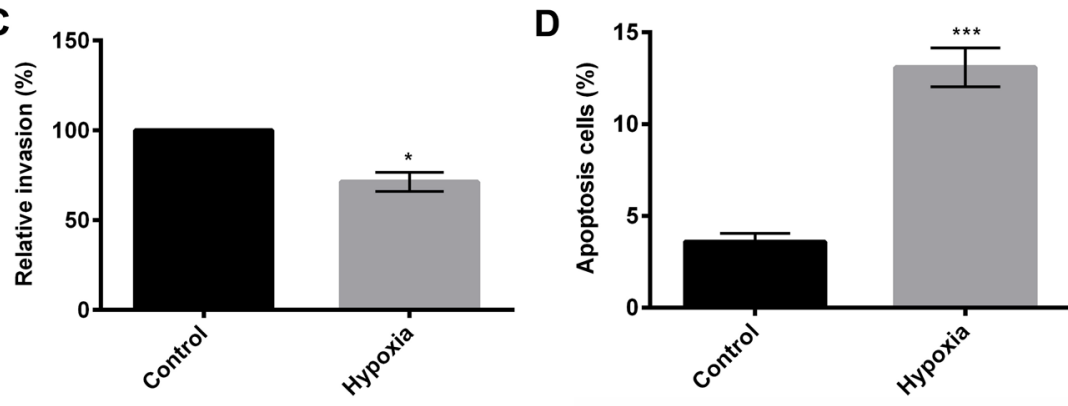

E
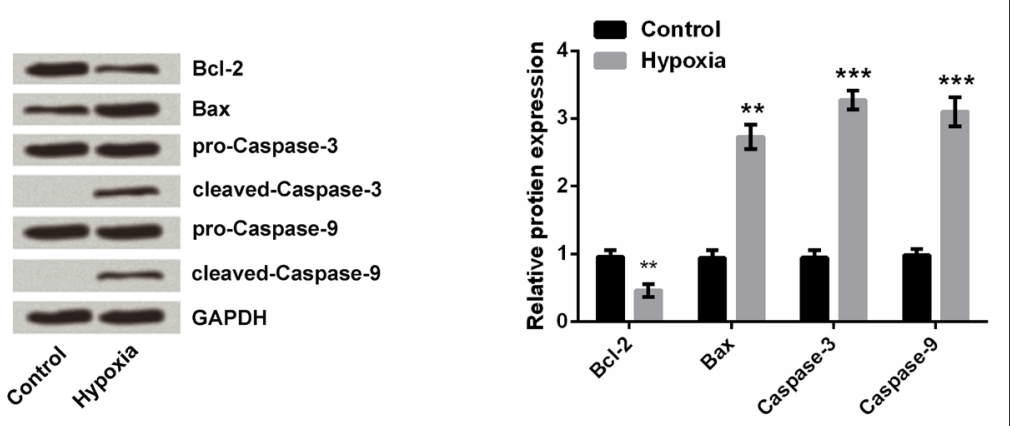
Fig. 2. Over-expression of MEG3 aggravates hypoxia injury in PC12 cells, while suppression of MEG3 alleviates the injury. (A) The expression of MEG3 in PC12 cells and primary neurons as quantified by RT-PCR. of MEG3 in PC12 cells as quantified by RTPCR; (B) Over-expression and suppression of MEG3 in PC12 cells as quantified by RT-PCR; Over-expression of MEG3 inhibits (C) cell viability; (D) migration; Over-expression of MEG3 aggravates hypoxia injury in PC12 cells inhibits (E) cell-invasion; (F) Promotes apoptotic cell rates; and regulated $(G)$ apoptosisrelated factors by western blot. *, $\mathrm{P}<0.05$; **, $\mathrm{P}<0.01$; $* * *, \mathrm{P}<0.001$.

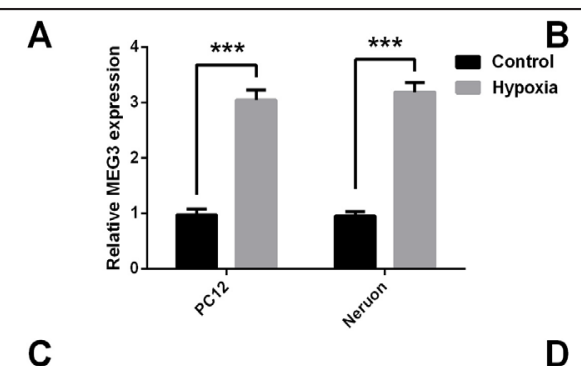

C
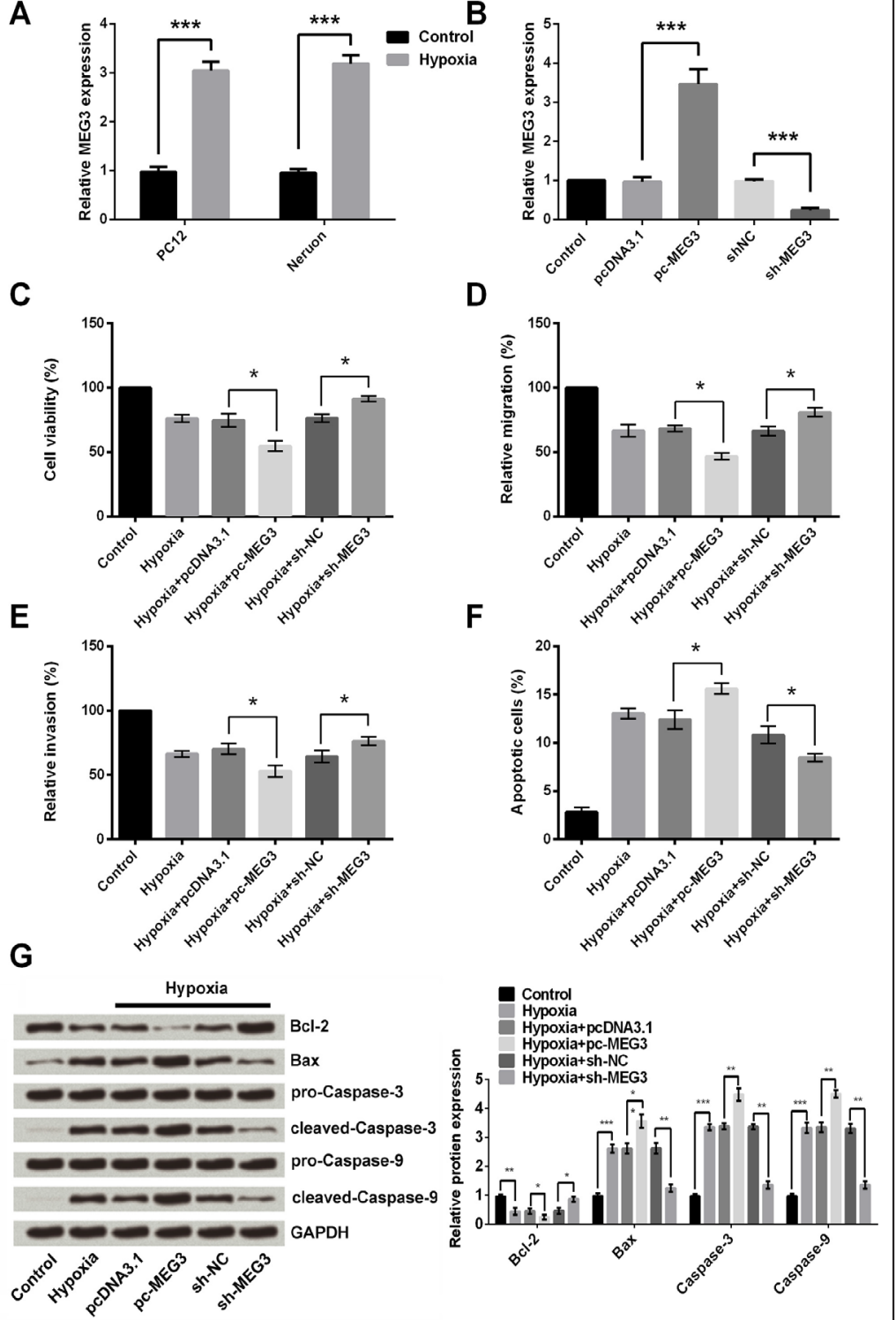

of MEG3 was decreased in PC12 cells transfected with sh-MEG3 as compared to the cells transfected with sh-NC $(\mathrm{P}<0.001 ;$ Fig. 2B). Subsequently, we explored the role of MEG3 in cell viability, migration and invasion, and apoptosis. . Cell viability as measured by trypan blue exclusion was decreased significantly in pc-MEG3 as compared to pcDNA3.1 $(\mathrm{P}<0.05$; Fig. 2C) and was found to significantly reduced in sh-MEG3 as compared to sh-NC $(\mathrm{P}<0.05$; Fig. 2C) when injured with hypoxia. Cell invasion and cell-migration were significantly decreased in pc-MEG3 as compared to pcDNA3.1 ( $\mathrm{P}<0.05$; Fig. 2E and 2D) and were also significantly declined in sh-MEG3 as compared to sh-NC $(\mathrm{P}<0.05$; Fig. 2E and 2D) when injured with hypoxia. Meanwhile, cell apoptosis measured using propidium iodide (PI) and fluorescein isothiocynate (FITC)-conjugated Annexin V staining was found to be significantly enhanced in pc-MEG3 as compared to pcDNA3.1 ( $\mathrm{P}<0.05$; Fig. $2 \mathrm{~F})$ and was also significantly increased in sh-MEG3 as compared to sh-NC $(\mathrm{P}<0.05$; Fig. $2 \mathrm{~F})$ when injured with hypoxia. Furthermore, we assessed the effect of MEG3 on the expression of core apoptosis-related factors. As shown in Fig. 2G, over-expression of MEG3 significantly reduced the expression of Bcl-2, and increased the levels of Bax, cleaved-Caspase- 3 and cleaved-Caspase- $9(\mathrm{P}<0.05$, or $\mathrm{P}<0.01)$. Opposite effects were found in down-regulation of MEG3 ( $\mathrm{P}<0.05$, or $\mathrm{P}<0.01$; Fig. 2G). 


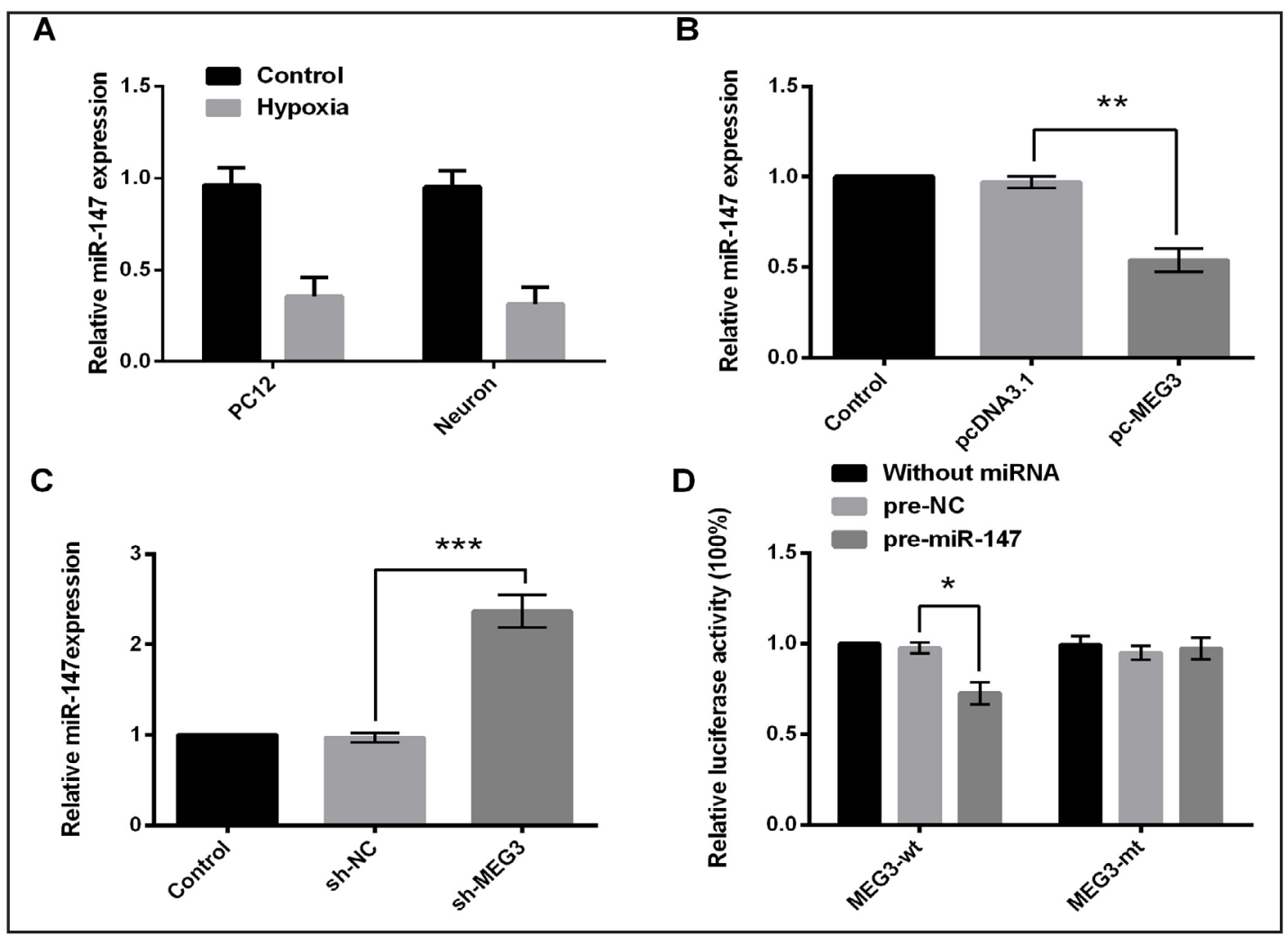

Fig. 3. miR-147 is a target of MEG3. (A) miR-147 is down-regulated in PC12 cells and primary cortical neurons after hypoxia. (B-C) MEG3 negatively regulates the expression of miR-147; (D) miR-147 is a target of MEG3 as determined by dual luciferase assay. *, $\mathrm{P}<0.05$; **, $\mathrm{P}<0.01$; ***, $\mathrm{P}<0.001$.

miR-147 is a target of MEG3

The expression of miR-147 was detected in PC12 cells and primary cortical neurons after hypoxia treatment. As shown in Fig. 3A, the expression of miR-147 was significantly declined in hypoxia-injured PC12 cells and primary cortical neurons. We then explored whether miR147 expression was regulated by MEG3 in PC12 cells. Significantly decreased expression of miR-147 as quantified by RT-PCR was observed in pcDNA3.1 when compared to pcMEG3 ( $\mathrm{P}<0.01$; Fig. 3B) and a significantly enhanced expression was observed in sh-MEG3 as compared to sh-NC $(\mathrm{P}<0.001$; Fig. $3 \mathrm{C})$. Furthermore, luciferase bioluminescence assay revealed that MEG3 negatively targeted miR-147 as indicated by decreased luminescence $(\mathrm{P}<0.05$; Fig. 3D).

Over-expression of MEG3 aggravates hypoxia injury by down-regulation of miR-147

Then, we further investigated whether MEG3 aggravated hypoxia injury by regulating miR-147 expression in PC12 cells. A significant decrease in cell-viability was observed in PC12 cells transfected with MEG3, referred to as pc-MEG3 when compared to pcDNA3.1 $(\mathrm{P}<0.05$; Fig. 4A), when injured by hypoxia. Further, a significant decrease in cell-viability was observed in pc-MEG3 cells with scramble as compared to pc-MEG3 cells with miR-147mimic $(\mathrm{P}<0.05$; Fig. 4A). Cell-migration and cell-invasion was decreased in pc-MEG3 when compared to pcDNA3.1 ( $<<0.05$; Fig. $4 \mathrm{~B}$ and $4 \mathrm{C})$ and was also significantly reduced in pcMEG3 cells with scramble as compared to pc-MEG3 cells with miR-147-mimic $(\mathrm{P}<0.05$; Fig. $4 \mathrm{~B}$ and $4 \mathrm{C}$ ), when injured by hypoxia. Apoptotic cells were significantly increased in pc-MEG3 when compared to pcDNA3.1 ( $\mathrm{P}<0.05$; Fig. 4D). An enhanced apoptosis was also observed in pc-MEG3 cells with scramble as compared to pc-MEG3 cells with miR-147-mimic $(\mathrm{P}<0.01$; Fig. 4D), when injured by hypoxia. Consistently, the regulation of MEG3 over-expression on 
Fig. 4. Over-expression of MEG3 aggravates hypoxia injury by down-regulation of miR-147. (A) Over-expression of MEG3 inhibits cell viability by down-regulation of miR-147; (B) Inhibits cell migration; (C) Over-expression of MEG3 inhibits cell invasion by down-regulation of miR-147; (D) Over-expression of MEG3 promotes cell apoptosis by downregulation of miR-147; (E) cell apoptosis measured by western blot. *, $\mathrm{P}<0.05$; **, $\mathrm{P}<0.01$; ***, $\mathrm{P}<0.001$.
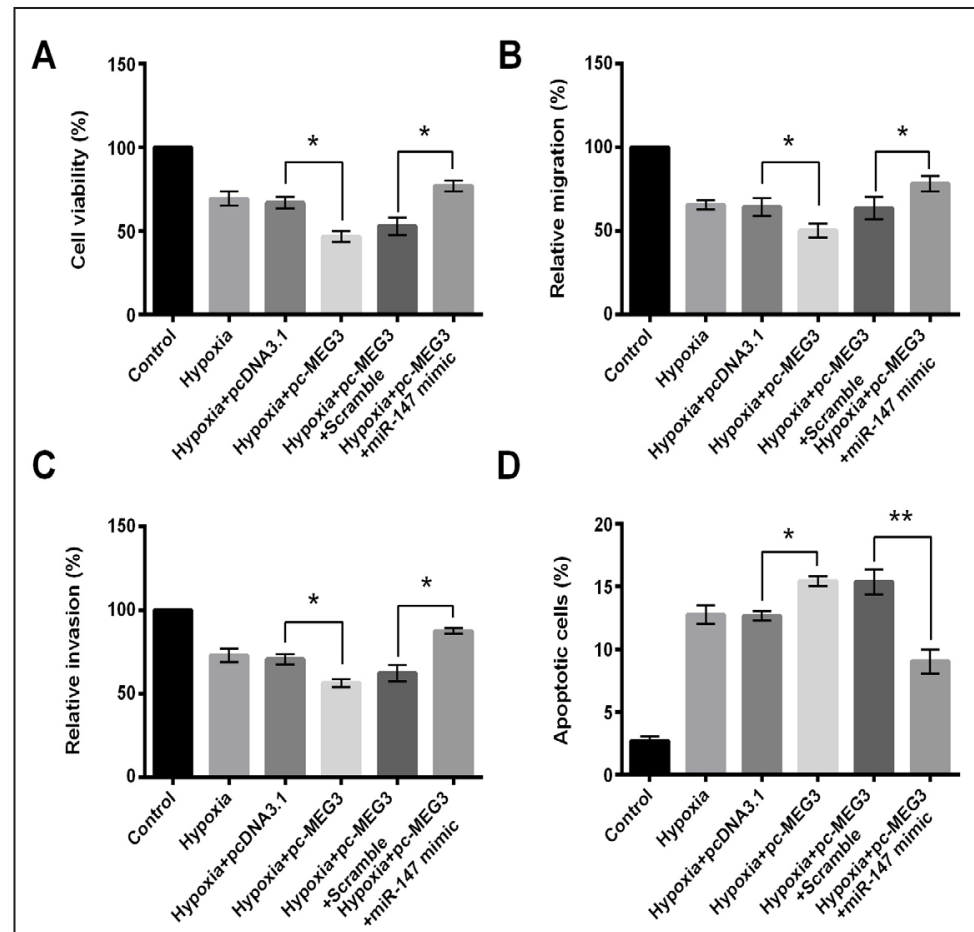

E
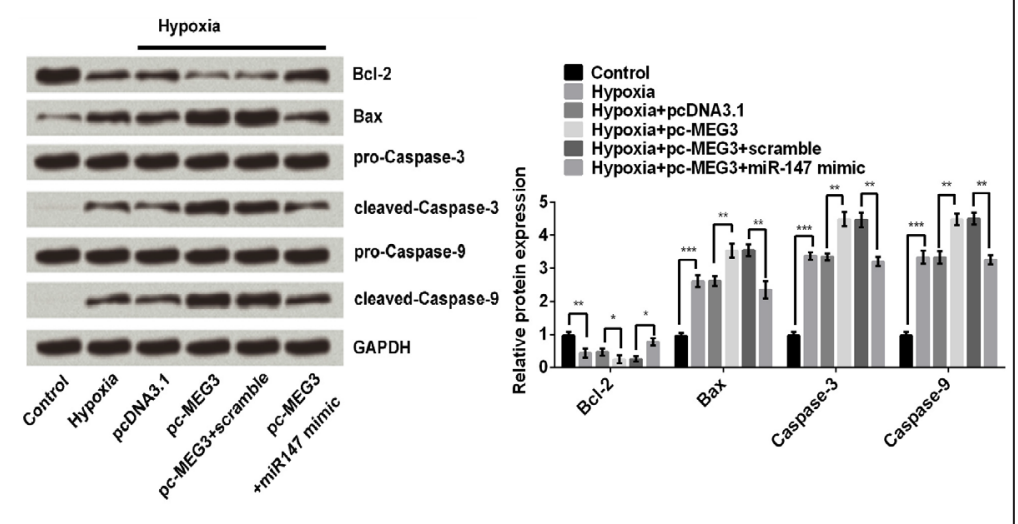

apoptosis-related factors expression was reversed by miR-147 mimic, as evidenced by upregulating Bcl-2, down-regulating Bax, cleaved-Capase-3 and cleaved-Capase- 9 expressions $(\mathrm{P}<0.05, \mathrm{P}<0.01$, or $\mathrm{P}<0.001$; Fig. 4E).

\section{MiR-147 negatively regulates Sox 2 expression, and Sox2 is a target of miR-147}

Sox2 mRNA and protein expressions were measured by qRT-PCR and western blot in PC12 cells and primary cortical neurons after hypoxia. As shown in Fig. 5A, Sox2 mRNA expression was significantly increased in PC12 cells and primary neurons after hypoxia $(\mathrm{P}<0.001)$. Similar results was observed in the protein expression, as increased Sox 2 protein expression in PC12 cells and neurons after hypoxia $(\mathrm{P}<0.001 ;$ Fig. $5 \mathrm{~A})$. We further investigated the regulation between miR-147 and Sox2. Sox2 expression as quantified by RT-PCR was significantly increased in scramble as compared to cells with miR-147-mimic $(\mathrm{P}<0.05$; Fig. 5A), when injured by hypoxia. Further, a significantly enhanced Sox2 expression was observed in cells with si-miR-147 as compared to siNC ( $\mathrm{P}<0.01$; Fig. $5 \mathrm{C})$. The regulation of protein expression was similar to mRNA changes $(\mathrm{P}<0.01$; Fig. 5D). Dual luciferase reporter assay showed that miR-147 negatively targeted Sox2 as indicated by decrease luminescence $(\mathrm{P}<0.05$; Fig. 5E). 
Fig. 5. MiR-147 negatively regulates Sox2 expression, and Sox2 is a target of miR-147. (A-B) (A) The mRNA expression of Sox 2 is upregulated in $\mathrm{PC} 12$ and primary cortical neurons after hypoxia. (B) The protein expression of Sox2 is up-regulated in PC12 and primary cortical neurons after hypoxia. (C-D) miR-147 negatively regulates Sox2 expression as quantified by RT-PCR and western blot; (E) Sox2 is a target of miR147 as determined by dual luciferase assay. *, $\mathrm{P}<0.05$; **, $\mathrm{P}<0.01$; ***, $\mathrm{P}<0.001$.

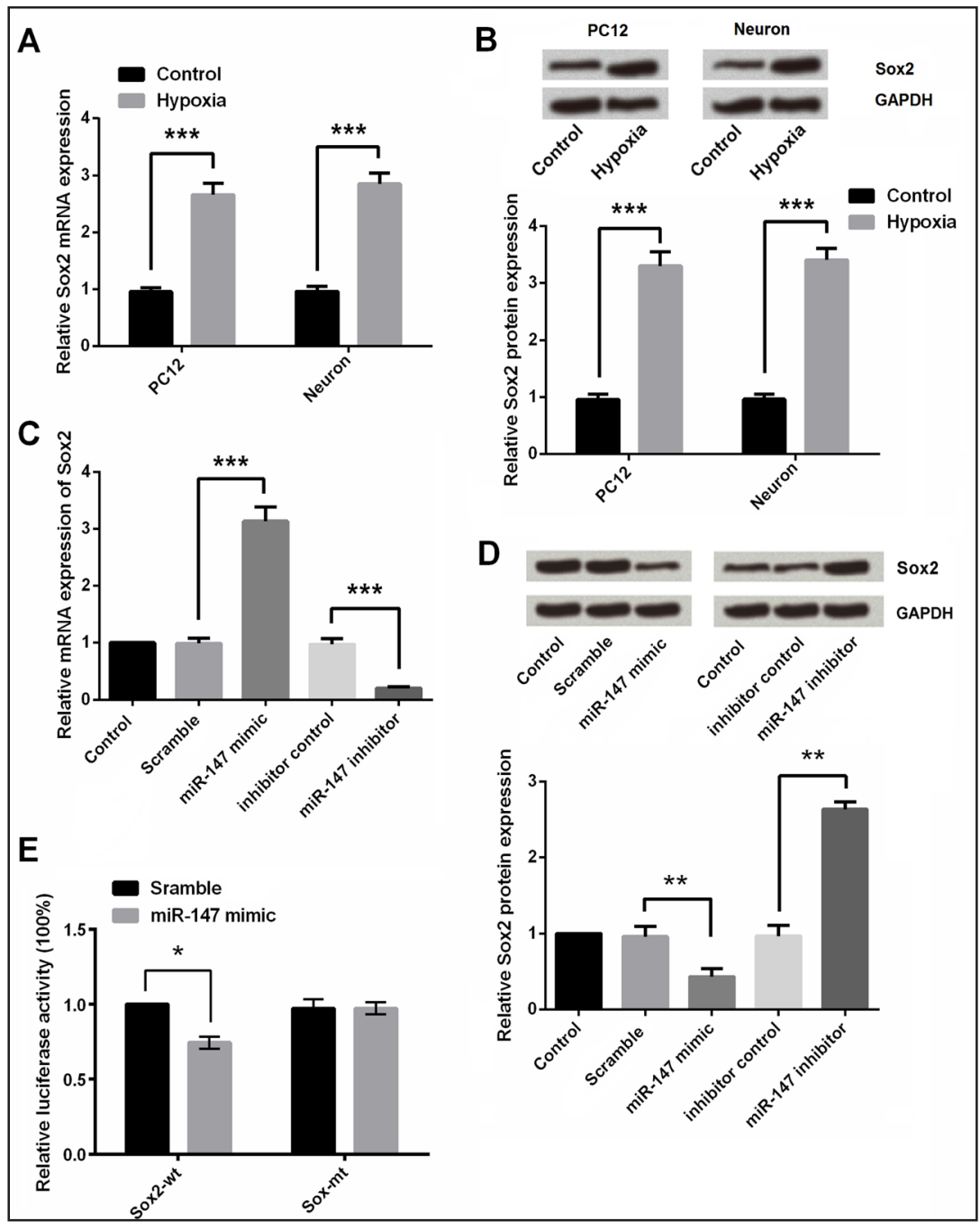

Sox 2 regulates the hypoxia-induced cell injury in PC12 cells

Sox-2 mRNA expression as quantified by RT-PCR was significantly enhanced in pEXSox 2 as compared to the expression in pEX, while was significantly enhanced in sh-NC as compared to sh-Sox $2(\mathrm{P}<0.001$; Fig. 6A). Further, Sox2 protein expressions showed the same changes as mRNA expressions $(\mathrm{P}<0.05$; Fig. $6 \mathrm{~B})$. Significantly enhanced cell-viability was observed in pEX cells when compared to pEX-Sox2 cells $(\mathrm{P}<0.05$; Fig. $6 \mathrm{C})$ when injured by hypoxia. Further, significantly enhanced cell-viability was also observed in sh-Sox2 as compared to sh-NC $(\mathrm{P}<0.05$; Fig. 6C), when injured by hypoxia. Moreover, cell-invasion and cell-migration was significantly reduced in pEX-Sox2 as compared to pEX $(\mathrm{P}<0.05$; Fig. 6D and $6 \mathrm{E})$ and was also significantly less in sh-NC when compared to sh-Sox2 $(\mathrm{P}<0.05$; Fig. 6D and 6E) when injured by hypoxia. As expected, apoptotic cells was significantly less in pEX cells when compared to pEX-Sox 2 cells $(\mathrm{P}<0.05$; Fig. $6 \mathrm{~F})$ and was also significantly reduced in sh-Sox 2 as compared to sh-NC $(\mathrm{P}<0.01$; Fig. $6 \mathrm{~F})$ when injured by hypoxia. Meanwhile, Sox 2 overexpression significantly inhibited the expression of $\mathrm{Bcl}-2$, and promoted the expression of Bax, cleaved-Capase- 3 and cleaved-Capase-9 ( $\mathrm{P}<0.05, \mathrm{P}<0.01$, or $\mathrm{P}<0.001$; Fig. 6G).

\section{Sox 2 regulated $N F-\kappa B$ and $W n t / \beta$-catenin signaling pathways}

As shown in Fig. 7, the expression of p-p65 and p-IкB $\alpha$ was increased in PC12 cells after hypoxia. Similar increase was found in Wnt-3a, Wnt-5a and $\beta$-catenin $(\mathrm{P}<0.01$, or $\mathrm{P}<0.001)$. However, overexpression of Sox 2 further activated the NF- $\mathrm{KB}$ pathway and Wnt/ $\beta$-catenin 


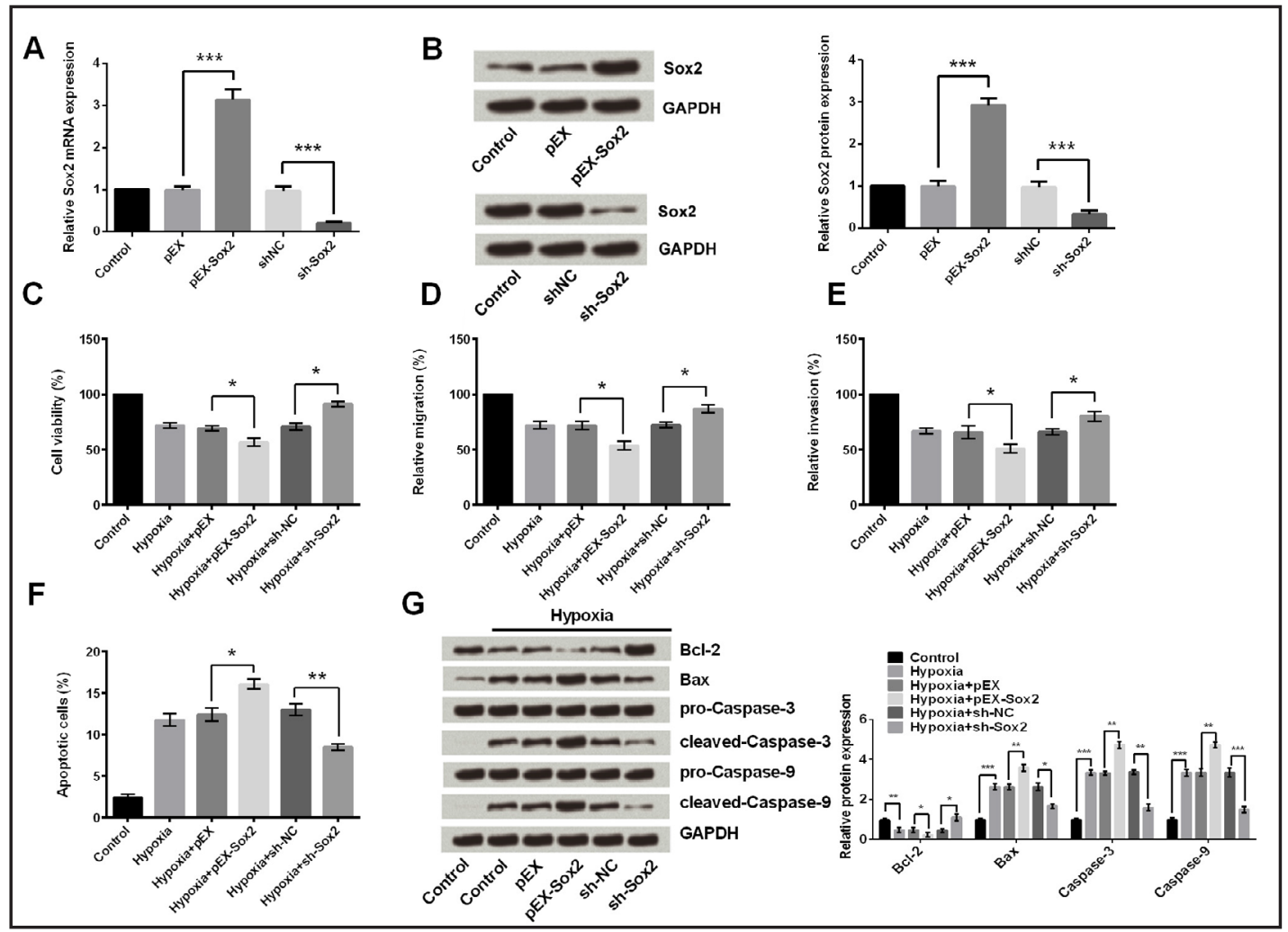

Fig. 6. Sox2 regulates the hypoxia-induced cell injury in PC-12 cells. (A-B) Over-expression of and knockdown of Sox2; (C-D) Over-expression of Sox2 inhibits cell viability and migration; (E-G) Over-expression of Sox2 inhibits invasion and promotes cell apoptosis. *, $\mathrm{P}<0.05$; **, $\mathrm{P}<0.01$; **, $\mathrm{P}<0.001$.

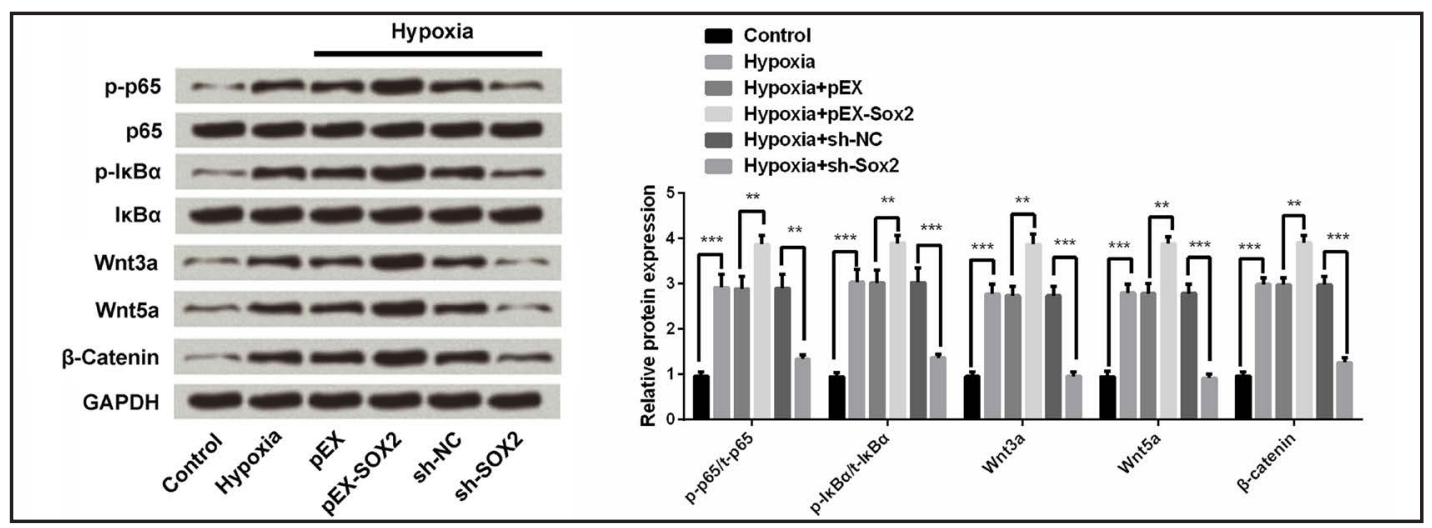

Fig. 7. Signaling pathways. Overexpression of Sox 2 aggravates hypoxia-induced cell injury by activating NF- $\kappa$ Band and Wnt/ $\beta$-catenin pathways in $\mathrm{PC}-12$ cells determined by western blots. ${ }^{* *}, \mathrm{P}<0.01 ; * * *, \mathrm{P}<0.001$.

pathway in PC12 cells, while Sox2 inhibition suppressed the two pathway, as significantly

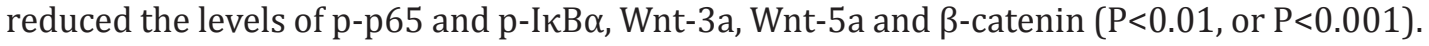

\section{Discussion}

The increasing incidence of cerebro-vascular disease, which is basically a nerve injury caused by acute cerebral ischemia has attracted the attention of scientists globally 


\section{Cellular Physiology Cell Physiol Biochem 2017;43:2457-2469 \begin{tabular}{ll|l} 
DOI: 10.1159/000484452 & $\begin{array}{l}\text { O 2017 The Author(s). Published by S. Karger AG, Basel } \\
\text { www.karger.com/cpb }\end{array}$ \\
\hline
\end{tabular} \\ Han et al.: Role of MEG3 in Cerebral Ischemia}

and considering the gravity of disease, it needs to be addressed urgently. It has become increasingly important to elucidate the molecular mechanisms of acute cerebral ischemiarelated neuronal injury [26]. As we have discussed previously, there are studies which have reported that cerebral miRNA and IncRNAs control epigenetic silencing or activation in mammal also get altered due to cerebral ischemia [27-29]. Moreover, long non-coding RNAs (LncRNAs), also go through changes in the post-stroke brain [30]. MEG3 was the first lncRNA to be found to act as a tumor suppressor and functions its anti-proliferative role through suppression of MDM2 expression with consequent increase of the p53 protein levels in human cancer cells $[21,31]$. Recently, it has been reported that MEG3 functions as a cell death promoter in ischemia and functionally interacts with p53 to mediate ischemic damage. The expression of MEG3 is up-regulated in the ischemic tissues of mice and induces primary cortical neurons and N2a cell lines after OGD injury [23]. In consist with previous report, our results demonstrated that MEG3 was up-regulated in hypoxia-injured PC12 cells and its overexpression aggravated hypoxia injury in PC12 cells. It suggested that MEG3 may play a vital role in hypoxia-induced injury in PC12 cells.

Previous study showed that miR-147 was down-regulated in glutamate treated cerebellar granule cells and up-regulation of miR-147 exerts a protective effect against glutamate excitotoxicity [32]. What's more, it has been reported that miR-147 could efficiently down-regulate endogenous APP expression in Neuro2A cells [33]. The present study revealed that miR-147 was reduced in PC12 cells after hypoxia, and it was negatively regulated by MEG3. What's more, we found that miR-147 mimic blocked the acceerative effect of MEG3 overexpression in hypoxia-induced injuries in PC12 cells. It may provide a new insight miR-147 might be involved in the process of neuronal damage. And our study was the first reported that miR-147 was regulated by MEG3.

Our results also indicated that Sox 2 was a direct target of miR-147 in PC12 cells and its expression was increased after hypoxia treatment. Emerging evidences have emphasized the role of Sox2 in the development of central nervous system (CNS). Sox2 is activated in the embryonic nervous system from the earliest stages of development, predominantly in the proliferating, undifferentiated precursors [34-36]. Meanwhile, Sox2 has been emerged as an important role in growth inhibition through cell cycle arrest and apoptosis in gastric cancers. And miR-126 is a miRNA that targets SoX2, and PLAC1 may be a novel downstream target gene of SOX2 in gastric cancer cells [37]. These reports indicated that Sox2 up-regulation may promote cell proliferation and inhibit cell apoptosis in neuronal cells. As expect, our results revealed that Sox2 overexpression reduced cell viability, migration and invasion, and promoted cell apoptosis. However, down-regulation of Sox2 exerted an opposite effect. In addition, we proved that miR-147 was a novel miRNA that targets Sox2 in PC12 cells.

In this study we have explored the effects and mechanisms of IncRNA MEG3 on the cell hypoxia injury in PC12 cells. Our study demonstrated that hypoxia induced cell injury in PC12 cells by inhibiting cell viability, migration and invasion and enhanced cell apoptosis. Over-expression of MEG3 enhanced hypoxia injuries in PC12 cells. Further, in this study we have also reported that miR-147 was a target of MEG3. Subsequently, over-expression of MEG3 aggravated hypoxia injury by down-regulation of miR-147. Moreover we found that miR-147 negatively regulated Sox2 expression and Sox2 was a target of miR-147. Taking into consideration the above mentioned facts and keeping in mind the interesting findings from our study, we can conclude that MEG3 enhances hypoxia induced injury in PC12 cells by down-regulating miR-147, and miR-147 further negatively regulated Sox 2 expression through targets its 3'-UTR.

\section{Disclosure Statement}

None declared. 


\section{Cellular Physiology Cell Physiol Biochem 2017;43:2457-2469

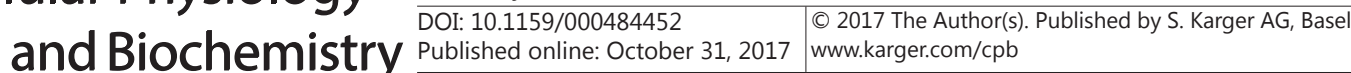

Han et al.: Role of MEG3 in Cerebral Ischemia

\section{References}

1 Ding Z, Tong WC, Lu XX, Peng HP: Hyperbaric Oxygen Therapy in Acute Ischemic Stroke: A Review. Interv Neurol 2014;2:201-211.

-2 Brongholi K, Souza DG, Bainy AC, Dafre AL, Tasca CI: Oxygen-glucose deprivation decreases glutathione levels and glutamate uptake in rat hippocampal slices. Brain Res 2006;1083:211-218.

-3 Barrett KM, Lal BK, Meschia JF: Stroke: Advances in Medical Therapy and Acute Stroke Intervention. Curr Cardiol Rep 2015;17:1-6.

-4 Zhou X, Gu J, Gu Y, He M, Bi Y, Chen J, Li T: Human Umbilical Cord-Derived Mesenchymal Stem Cells Improve Learning and Memory Function in Hypoxic-Ischemic Brain-Damaged Rats via an IL-8-Mediated Secretion Mechanism Rather than Differentiation Pattern Induction. Cell Physiol Biochem 2015;35:2383-2401.

5 Adhami F, Liao G, Morozov YM, Schloemer A, Schmithorst VJ, Lorenz JN, Dunn RS, Vorhees CV, Wills-Karp M, Degen JL: Cerebral Ischemia-Hypoxia Induces Intravascular Coagulation and Autophagy. Am J Pathol 2015;169:566-583.

6 Baron JC: Perfusion thresholds in human cerebral ischemia: historical perspective and therapeutic implications. Cerebrovasc Dis 2001;11:2-8.

7 Sobesky J, Zaro WO, Lehnhardt FG, Hesselmann V, Neveling M, Jacobs A, Heiss WD: Does the mismatch match the penumbra? Magnetic resonance imaging and positron emission tomography in early ischemic stroke. Stroke 2005;36:980-985.

8 Adhami F, Liao G, Morozov YM, Schloemer A, Schmithorst VJ, Lorenz JN, Dunn RS, Vorhees CV, Wills-Karp M, Degen JL, Davis RJ, Mizushima N, Rakic P, Dardzinski BJ, Holland SK, Sharp FR, Kuan C-Y: Cerebral IschemiaHypoxia Induces Intravascular Coagulation and Autophagy. Am J Pathol 2006;169:566-583.

-9 Fan J, Liu Y, Yin J, Li Q, Li Y, Gu J, Cai W, Yin G: Oxygen-Glucose-Deprivation/Reoxygenation-Induced Autophagic Cell Death Depends on JNK-Mediated Phosphorylation of Bcl-2. Cell Physiol Biochem 2016;38:1063-1074.

10 Wei R, Zhang R, Xie Y, Shen L, Chen F: Hydrogen Suppresses Hypoxia/Reoxygenation-Induced Cell Death in Hippocampal Neurons Through Reducing Oxidative Stress. Cell Physiol Biochem 2015;36:585-598.

11 Khot S, Tirschwell DL: Long-term neurological complications after hypoxic-ischemic encephalopathy. Semin Neurol 2006;26:422-431.

12 Yee T, Gronner A, Knight RT: CT findings of hypoxic basal ganglia damage. South Med J 1994;87:624-626.

13 Zhang L, Zhang ZG, Chopp M: The neurovascular unit and combination treatment strategies for stroke. Trends Pharmacol Sci 2012;33:415-422.

14 Jickling GC, Ander BP, Zhan X, Noblett D, Stamova B, Liu D: microRNA Expression in Peripheral Blood Cells following Acute Ischemic Stroke and Their Predicted Gene Targets. PLoS One 2014;9:e99283.

15 Khoshnam SE, Winlow W, Farbood Y, Moghaddam HF, Farzaneh M: Emerging Roles of microRNAs in Ischemic Stroke: As Possible Therapeutic Agents. J Stroke 2017;19:166-187.

16 Ly JV, Zavala JA, Donnan GA: Neuroprotection and thrombolysis: combination therapy in acute ischaemic stroke. Expert Opin Pharmacother 2006;7:1571-1581.

-17 Zhou RM, Wang XQ Yao J, Shen Y, Chen SN, Yang H, Jiang Q, Yan B: Identification and characterization of proliferative retinopathy-related long noncoding RNAs. Biochem Biophys Res Commun 2015;465:324-330.

18 Saugstad JA: Non-Coding RNAs in Stroke and Neuroprotection. Front Neurol 2015;6:50.

19 Wu P, Zuo X, Deng H, Liu X, Liu L, Ji A: Roles of long noncoding RNAs in brain development, functional diversification and neurodegenerative diseases. Brain Res Bull 2013;97:69-80.

-20 Wu Z, Wu P, Zuo X, Yu N, Qin Y, Xu Q He S, Cen B, Liao W, Ji A: LncRNA-N1LR Enhances Neuroprotection Against Ischemic Stroke Probably by Inhibiting p53 Phosphorylation. Mol Neurobiol 2016. Doi: 10.1007/ s12035-016-0246-z

21 Benetatos L, Vartholomatos G, Hatzimichael E: MEG3 imprinted gene contribution in tumorigenesis. Int J Cancer 2011;129:773-779.

22 Zhang X, Gejman R, Mahta A, Zhong Y, Rice KA, Zhou Y, Cheunsuchon P, Louis DN, Klibanski A: Maternally expressed gene 3, an imprinted noncoding RNA gene, is associated with meningioma pathogenesis and progression. Cancer Res 2010;70:2350-2358.

23 Yan H, Yuan J, Gao L, Rao J, Hu J: Long noncoding RNA MEG3 activation of p53 mediates ischemic neuronal death in stroke. Neuroscience 2016;337:191-199. 


\section{Cellular Physiology Cell Physiol Biochem 2017;43:2457-2469 \begin{tabular}{ll|l} 
DOI: 10.1159/000484452 & $\begin{array}{l}\text { O 2017 The Author(s). Published by S. Karger AG, Basel } \\
\text { www.karger.com/cpb }\end{array}$ \\
\hline and Biochemistry Published online: October 31, 201
\end{tabular}}

Han et al.: Role of MEG3 in Cerebral Ischemia

24 Zhou GY, Zhou SN, Lou ZY, Zhu CS, Zheng XP, Hu XQ: Translocation and neuroprotective properties of transactivator-of-transcription protein-transduction domain\&ndash;neuroglobin fusion protein in primary cultured cortical neurons. Biotechnol Appl Biochem 2008;49:25-33.

-25 Hsieh TC, Wijeratne EK, Liang JY, Gunatilaka AL, Wu JM: Differential control of growth, cell cycle progression, and expression of NF-kappaB in human breast cancer cells MCF-7, MCF-10A, and MDAMB-231 by ponicidin and oridonin, diterpenoids from the chinese herb Rabdosia rubescens. Biochem Biophys Res Commun 2005;337:224-231.

-26 Z L, X Y, J S, MT C, WK W: MicroRNA in intervertebral disc degeneration. Cell Prolif 2015;48:278-283.

27 Dharap A, Bowen K, Place R, Li LC, Vemuganti R: Transient focal ischemia induces extensive temporal changes in rat cerebral MicroRNAome. J Cereb Blood Flow Metab 2009;29:675-687.

-28 Dharap A, Pokrzywa C, Vemuganti R: Increased binding of stroke-induced long non-coding RNAs to the transcriptional corepressors Sin3A and coREST. ASN Neuro 2013;5:283-289.

-29 Zhang J, Yuan L, Zhang X, Hamblin MH, Zhu T, Meng F, Li Y, Chen YE, Yin KJ: Altered long non-coding RNA transcriptomic profiles in brain microvascular endothelium after cerebral ischemia. Exp Neurol 2015;277:162-170.

30 Mehta SL, Kim T, Vemuganti R: Long Noncoding RNA FosDT Promotes Ischemic Brain Injury by Interacting with REST-Associated Chromatin-Modifying Proteins. J Neurosci 2015;35:16443-16449.

31 Zhang X, Zhou Y, Mehta KR, Danila DC, Scolavino S, Johnson SR, Klibanski A: A pituitary-derived MEG3 isoform functions as a growth suppressor in tumor cells. J Clin Endocrinol Metab 2003;88:5119-5126.

-32 Hunsberger JG, Fessler EB, Chibane FL, Yan L, Maric D, Elkahloun AG, Chuang DM: Mood stabilizerregulated miRNAs in neuropsychiatric and neurodegenerative diseases: identifying associations and functions. Am J Transl Res 2013;5:450-464.

-33 Charlotte D, Frédéric C, Paul M, Hébert SS: Alzheimer-specific variants in the 3'UTR of Amyloid precursor protein affect microRNA function. Mol Neurodegener. 2011;6:70.

-34 Pevny LH, Nicolis SK: Sox2 roles in neural stem cells. Int J Biochem Cell Biol 2010;42:421-424.

-35 Pevny L, Placzek M: SOX genes and neural progenitor identity. Curr Opin Neurobiol 2005;15:7-13.

-36 Wegner M, Stolt CC: From stem cells to neurons and glia: a Soxist's view of neural development. Trends Neurosci 2005;28:583-588.

37 Otsubo T, Akiyama Y, Hashimoto Y, Shimada S, Goto K, Yuasa Y: MicroRNA-126 Inhibits SOX2 Expression and Contributes to Gastric Carcinogenesis. PLoS One 2011;6:e16617. 